\title{
Quantifying the clear-sky temperature inversion frequency and strength over the Arctic Ocean during summer and winter seasons from AIRS profiles
}

\author{
A. Devasthale ${ }^{1}$, U. Willén ${ }^{2}$, K.-G. Karlsson ${ }^{1}$, and C. G. Jones ${ }^{2}$ \\ ${ }^{1}$ Remote Sensing Division, Swedish Meteorological and Hydrological Institute, Norrköping, Sweden \\ ${ }^{2}$ Rossby Center, Swedish Meteorological and Hydrological Institute, Norrköping, Sweden
}

Received: 7 December 2009 - Published in Atmos. Chem. Phys. Discuss.: 4 February 2010

Revised: 24 May 2010 - Accepted: 6 June 2010 - Published: 22 June 2010

\begin{abstract}
Temperature inversions are one of the dominant features of the Arctic atmosphere and play a crucial role in various processes by controlling the transfer of mass and moisture fluxes through the lower troposphere. It is therefore essential that they are accurately quantified, monitored and simulated as realistically as possible over the Arctic regions. In the present study, the characteristics of inversions in terms of frequency and strength are quantified for the entire Arctic Ocean for summer and winter seasons of 2003 to 2008 using the AIRS data for the clear-sky conditions. The probability density functions (PDFs) of the inversion strength are also presented for every summer and winter month.

Our analysis shows that although the inversion frequency along the coastal regions of Arctic decreases from June to August, inversions are still seen in almost each profile retrieved over the inner Arctic region. In winter, inversions are ubiquitous and are also present in every profile analysed over the inner Arctic region. When averaged over the entire study area $\left(70^{\circ} \mathrm{N}-90^{\circ} \mathrm{N}\right)$, the inversion frequency in summer ranges from 69 to $86 \%$ for the ascending passes and $72-86 \%$ for the descending passes. For winter, the frequency values are $88-91 \%$ for the ascending passes and 89 $92 \%$ for the descending passes of AIRS/AQUA. The PDFs of inversion strength for the summer months are narrow and right-skewed (or positively skewed), while in winter, they are much broader. In summer months, the mean values of inversion strength for the entire study area range from 2.5 to $3.9 \mathrm{~K}$, while in winter, they range from 7.8 to $8.9 \mathrm{~K}$. The standard deviation of the inversion strength is double in winter compared to summer. The inversions in the summer months of
\end{abstract}

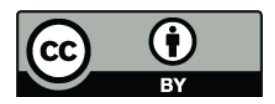

Correspondence to: A. Devasthale (abhay.devasthale@smhi.se)
2007 were very strong compared to other years. The warming in the troposphere of about $1.5-3.0 \mathrm{~K}$ vertically extending up to $400 \mathrm{hPa}$ was observed in the summer months of 2007 .

\section{Introduction and background}

The Arctic region is warming at twice the rate of rest of the world (ACIA, 2004). Both observational and modelling studies indicate high susceptibility of this region to undergo changes as the anthropogenic emissions increase. Due to very limited understanding and poor quantification of the complex feedback processes, uncertainties (and inter-model differences) in the future estimates of climate change in the Arctic are very high. An accurate quantification and monitoring of the essential climate variables (ECVs) in this region help in partly reducing the uncertainties. Space-based observations from satellite sensors are becoming increasingly important in this context due to their ability to provide crucial information on ECVs with improving accuracy and at the spatio-temporal scales required to capture the large-scale statistics of such variables.

One of the dominant features of the Arctic atmosphere is the lower tropospheric temperature inversions. Any change in the Arctic climate system may influence the characteristics of the inversions (frequency, strength, depth, etc.), and this may in turn have feedback on other processes in the region. Inversion strength controls the transfer of mass and moisture fluxes through the lowermost troposphere. Increased levels of pollutants capping the inversions layer have also been reported. Precise knowledge of the characteristics of inversions is also essential for accurate ice motion and glacier mass balance simulations. Therefore, the importance of studying the inversion characteristics has been long appreciated, and

Published by Copernicus Publications on behalf of the European Geosciences Union. 
several studies have been carried out in this context (Bradley et al., 1992; Serreze et al., 1992; Kahl et al., 1996; Liu and Key, 2003; Liu et al., 2006; Mernild and Liston, 2009; Sedlar and Tjernstrom, 2009; Tjernstrom and Graversen, 2009). Most of these studies use measurements from radiosondes and although they provide information at very high vertical resolution, they do not cover the entire Arctic Ocean, and as a result, information on the spatial variability of inversions is largely lacking. The work by Liu et al. (2006) presents useful information on the inversion strength in the Arctic using long-term satellite sensor data, but it is limited to only winter months. They also do not provide information on the inversion frequency. The data used are of very coarse vertical resolution, since their algorithm relies on two channels of the HIRS instrument which peak in their sensitivity at the surface and at $650 \mathrm{hPa}$.

With the launch of the Atmospheric Infrared Sounder (AIRS) onboard NASA's Aqua satellite in 2002, it is now possible to quantify the vertical structure of temperature and its variability at an unprecedented accuracy and vertical resolution from space (e.g. see the recent work by Kahn and Teixeira, 2009). In the present study, we characterize the lower tropospheric temperature inversions in terms of frequency and strength over the Arctic Ocean $\left(70^{\circ} \mathrm{N}-\right.$ $90^{\circ} \mathrm{N}$ ). We discuss the spatio-temporal variability of inversion characteristics in detail and relate the record sea-ice minimum of summer 2007 in this context. The description of the AIRS data is given in Sect. 2 and the results are presented in Sect. 3. Section 4 summarizes the main conclusions from this study.

\section{AIRS temperature profiles}

We use the AIRS level 3 (L3) Version 5 research quality product (AIRX3STD) for the present study (Olsen et al., 2007b). The daily product at the spatial resolution of $1 \times 1$ degrees is used. Temperature retrievals at the surface, $1000 \mathrm{hPa}, 925 \mathrm{hPa}, 850 \mathrm{hPa}, 700 \mathrm{hPa}, 600 \mathrm{hPa}, 500 \mathrm{hPa}$, and $400 \mathrm{hPa}$ levels are used in the analysis. The data for the summer (June-August) and winter (December-February) months from 2003 to 2008 are processed. The reason for analyzing summer and winter seasons is twofold. First, the literature review shows that inversion frequency and strength are highest in winter and lowest in summer over the Arctic (Bradley et al., 1992; Kahl et al., 1996; Serreze et al., 1992; Tjernström and Graversen, 2008). Therefore, it is interesting to quantify these two contrasting episodes and, in future, examine how well they are simulated by climate models. Second, it has been observed that satellite sensor retrievals of cloud top height, which require an ancillary knowledge on temperature inversions, are sensitive to inversion strength (Karlsson and Dybbroe, 2010). It is very challenging to assign cloud top height retrieved from the passive imaging sensors in such two contrasting episodes. Therefore, an assessment of the statistics of inversion strength and frequency is required to subsequently understand the expected bias in such retrievals.

The data from the ascending and descending passes of AIRS are analysed separately. When the Aqua satellite, which has the local equator crossing time of 13:30, is orbiting the Earth from north to south (or southbound), it is in a descending pass, and vice versa for an ascending pass. For tropics and mid-latitudes, ascending passes occur during local daytime conditions and descending passes during nighttime conditions due to polar sun-synchronous orbital configuration of the Aqua satellite. But for the Arctic region, the sun is permanently above the horizon during the summer months and below during the winter months. Thus, the conventional definitions of "day/night" for "ascending/descending" passes of satellite do not hold true at these latitudes.

A wealth of literature is available on the validation of AIRS temperature retrievals, including over the regions at high latitudes (Special issue in JGR - Divakarla et al., 2006; Fetzer, 2006; Gao et al., 2006). Rigorous quality control is applied while selecting the profiles for the analysis. It should also be noted that only high quality measurements from the level 2 products are used to derive the level 3 products avoiding the fallback cases (Olsen et al., 2007a,b). In the present study, if the total cloud cover is zero and if the temperature retrievals at all of the above levels are available, only then the profile is used for analysis.

Starting from the surface skin temperature, we recursively search for the warmer temperature at lower pressure level above (up to $400 \mathrm{hPa}$ ), and if such condition occurs, we consider inversion to be present in the retrieved profile.

\section{Results and discussion}

The results are organized as follows. First we present the statistics on the frequency of inversions during the individual summer and winter months. Then, probability density functions (PDFs) for the maximum inversion strength are quantified for the individual months and years for the summer and winter seasons. The composites of the spatial structure of the inversion strength are shown. Inter-annual variations in the spatial pattern of the inversion strength are also discussed. These results are discussed in the context of sea-ice minimum of the summer of 2007. The observed relationship between the surface skin temperature and inversion strength is discussed briefly. When appropriate, the qualitative comparisons are made with the previous studies that use radiosonde data or the results from special campaigns over Arctic.

\subsection{Inversion frequency}

The composites of the mean inversion frequency (20032008) for the individual summer and winter months are shown in Figs. 1 and 2, respectively. Differences in the inversion frequency in the ascending and the descending passes are very small. This is in a way expected considering 

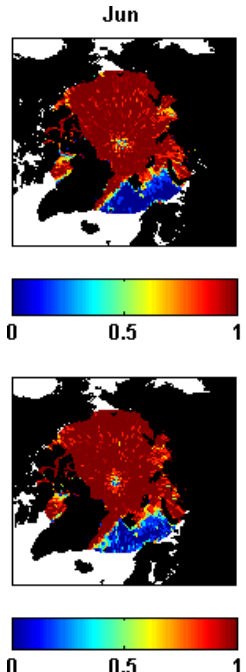
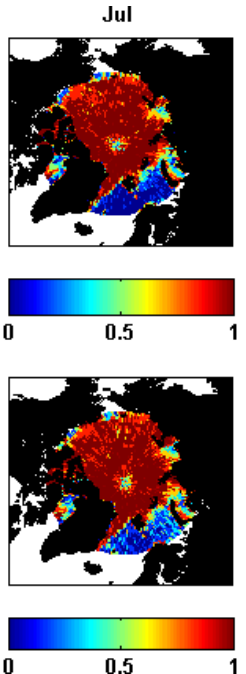
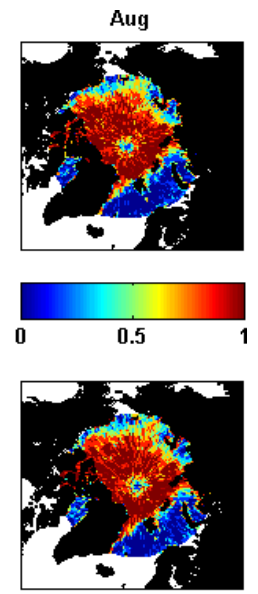

0

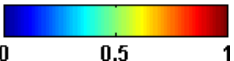

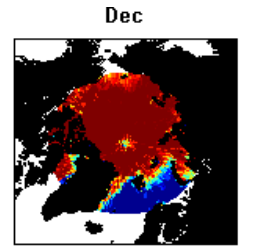
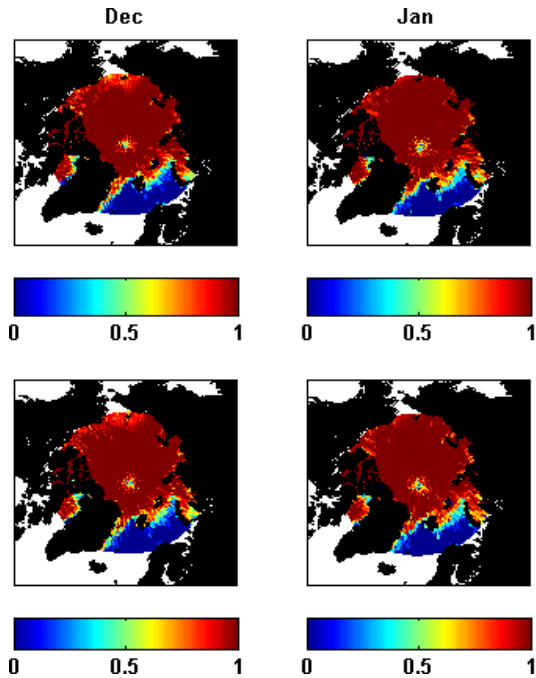

Fig. 1. The mean inversion frequency (averaged over 2003-2008) for the summer months over the Arctic Ocean $\left(70^{\circ} \mathrm{N}-90^{\circ} \mathrm{N}\right)$. Top and bottom rows are for the ascending and descending passes.

the stability of the atmosphere and small diurnal variations over this region. It also indirectly provides a hint at the consistency of the AIRS temperature retrievals. The inversion frequency along the coastal regions in Arctic decreases from June to August. However, over the inner Arctic, inversions are still seen in almost every profile retrieved. In winter, the overall inversion frequency is high compared to summer months, and inversions are ubiquitous over the inner Arctic Ocean. When averaged over the entire study area $\left(70^{\circ} \mathrm{N}-\right.$ $90^{\circ} \mathrm{N}$ ), the inversion frequency in summer ranges from 69 to $84 \%$ for the ascending passes and $72-86 \%$ for the descending passes. For winter, the frequency values are $88-91 \%$ for the ascending passes and $89-92 \%$ for the descending passes. The net radiation in the lowermost troposphere has a large bearing on inversion frequency and sustenance of stable layers at very high latitudes. In winter, the net emission exceeds energy input from the Sun. The resulting negative radiative imbalance is mainly responsible for the relatively high inversion frequency in winter compared to summer when this imbalance is either weak or positive. The turbulent mixing due to frontal systems and advection from mid-latitudes further lead to the reduced stability during summer months.

Such high values of inversion frequencies, even in summer, and their ubiquitous nature over the certain locations in the inner Arctic in both summer and winter seasons have been previously reported. For example, Serreze et al. (1992) using rawinsonde data and Soviet Drifting Station data show that the parts of Eurasian Arctic Ocean experience inversion frequencies greater than $80 \%$ even in summer, while the frequencies are very close to $100 \%$ in winter (esp. over inner Arctic). More recently, Tjernström and Graversen (2009) using one year in-situ data (1997-1998) from the Surface Heat Budget of the Arctic (SHEBA) experiment, over the region

Fig. 2. Same as in Fig. 1, but for the winter months.

located north of Alaska, reported that the inversions were practically present $(99.5 \%)$ in all of their soundings. Our analysis results compare well with their findings.

\subsection{Inversion strength}

The PDFs of the inversion strength for the summer and winter months are shown in Figs. 3 and 4, respectively. The bin size on the $x$-axis is $0.25 \mathrm{~K}$. The PDFs are plotted for all individual months and years separately and are computed for the entire study area. The PDFs in the summer months are narrow and right-skewed (or positively skewed). The inter-annual variability in the distribution is evident in the plots. The distributions for the years 2003, 2004, 2006, and 2008 follow approximately similar pattern, while the years 2005 and even more so 2007 stand out clearly showing much broader distributions. The year 2007 experienced one of the lowest sea-ice minimum events. The PDFs show that the inversions were very strong in summer of 2007 compared to "normal" years. The PDFs in 2007 also have the dual peak structure. The mean values of inversion strength for the entire study area range from 2.5 to $3.9 \mathrm{~K}$ in summer (JJA 2003-2008). In winter, the PDFs are much broader and show much higher inter-annual variability compare to summer. The mean values of inversion strength for the entire study area range from 7.8 to $8.9 \mathrm{~K}$ (DJF 2002-2008). The standard deviation of the inversion strength is about $1.5 \mathrm{~K}$ for the summer months, while it is about $3.0 \mathrm{~K}$ for winter months. Since the differences in the ascending and the descending passes are very small, only the analysis of the ascending passes is presented hereafter for brevity.

The spatial structure of the inversion strength from the ascending passes is shown in Fig. 5. Top row shows the mean composites for the summer months (2003-2008) and the bottom row for the winter months. Note that the scale 

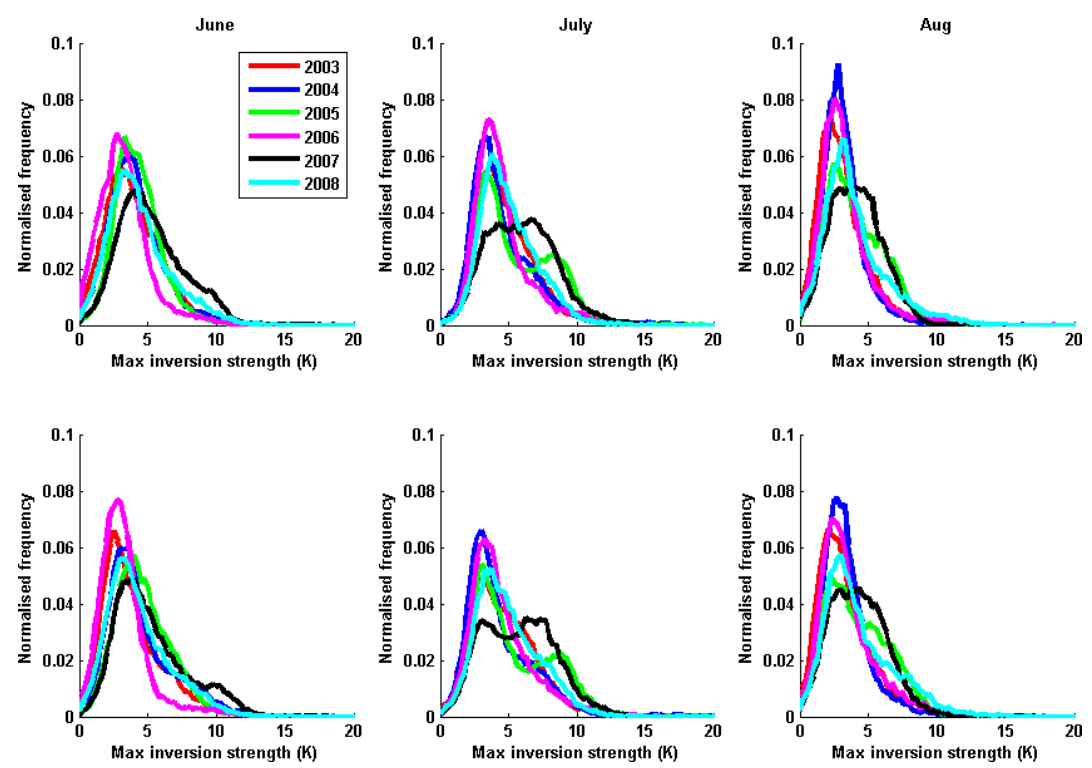

Fig. 3. The PDFs of inversion strength (in K) for the summer months. Top and bottom rows are for the ascending and descending passes.
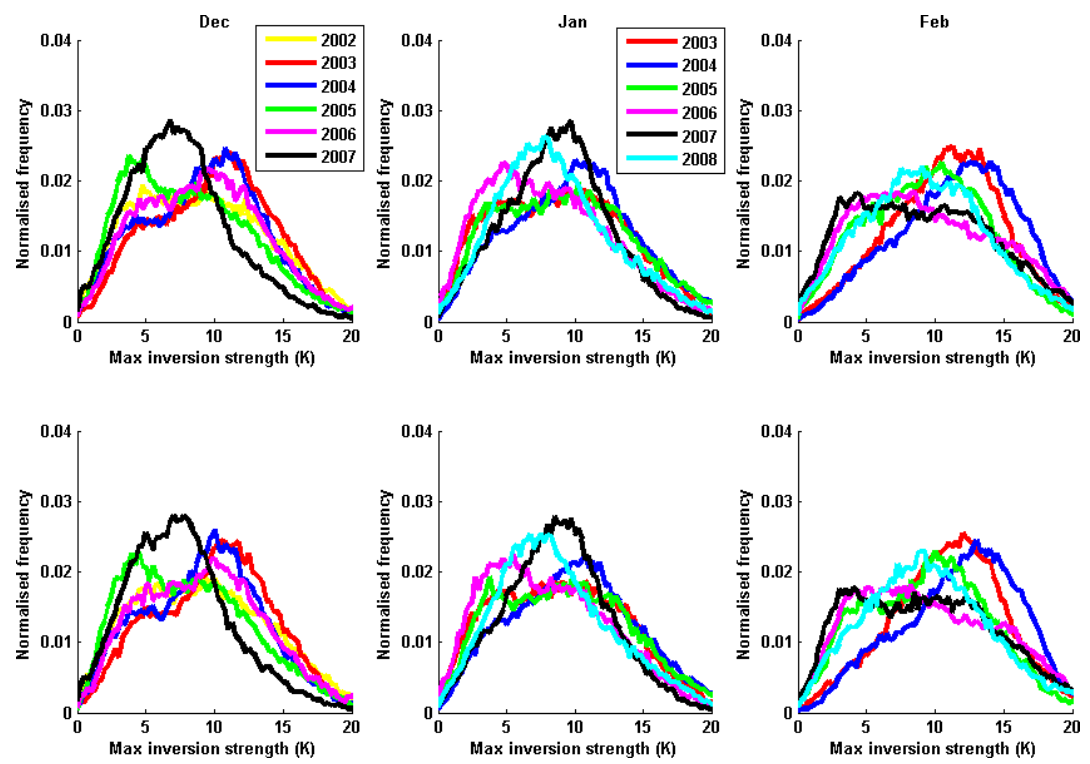

Fig. 4. Same as in Fig. 3, but for the winter months.

of inversion strength is doubled for the winter months. East Siberian Sea and the Beaufort Sea show very high inversion strength in the range of 4 to $8 \mathrm{~K}$ (in mean values) in June months. In July, additionally the parts of Western Greenland Sea and the Lincoln Sea also show high inversion strength. The inversion strength is reduced considerably in August. In December and January months, the area north of Greenland and the northeastern parts of North American Arctic show very high inversion strength ranging from 7 to $15 \mathrm{~K}$ (in mean values). In February, the entire inner Arctic show very high inversion strength. The intricate pattern of spatial variability in inversion strength is evident for all cases.
Previous studies also report a similar range of magnitudes of the inversion strength for winter. For example, Serreze et al. (1992) show that the mean inversion strength for the Eurasian Arctic ranges from 8 to $12 \mathrm{~K}$. Kahl et al. (1996) used nearly 30000 temperature profiles over the Arctic Ocean (from 1950-1990) and showed the median inversion strength ranging from 6 to $12 \mathrm{~K}$. For the SHEBA experiment area, Tjernström and Graversen (2009) computed the inversion strength in the range of 8 to $10 \mathrm{~K}$. Liu et al. (2006), using HIRS sensor data, estimated the inversion strength in the range of 8 to $15 \mathrm{~K}$ over the Arctic Ocean. The spatial pattern of the inversions strength in their study closely matches with our results in winter. 

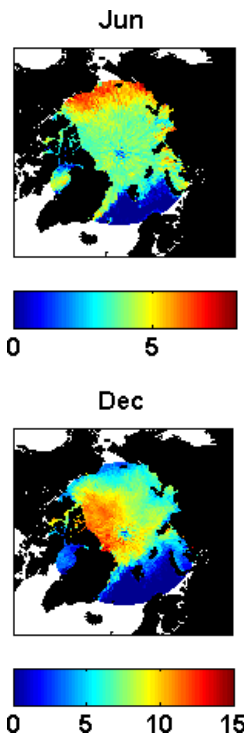
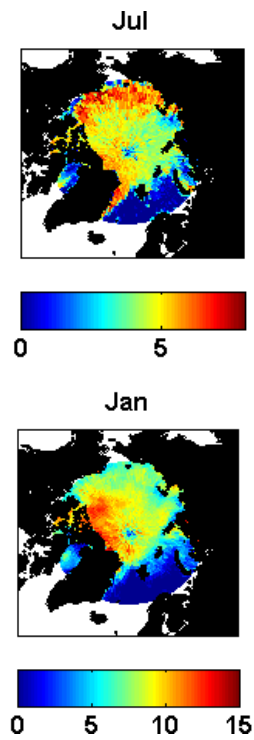
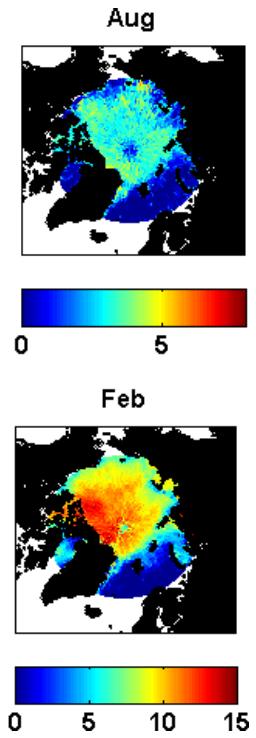

Fig. 5. The spatial pattern of inversion strength (in K) averaged over 2003-2008 for summer (top row) and winter (bottom row) months from the ascending passes. Note that the scale for the winter months is doubled.

If the inversions are surface-based (which is most likely to happen in winter), the surface temperature plays an important role in controlling the inversion strength. This is clearly reflected for the winter months in Fig. 6 which shows the joint histograms of surface temperature and inversion strength (for summer and winter months composited for 2003-2008). The negative correlation between surface temperature and inversion strength can be seen for the winter months. Since the formation mechanisms of inversion are most likely to be different in summer and winter months (radiation loss being the main controlling factor in winter, while the advection of warm air from low latitudes dominating in summer resulting in elevated inversions), it is also not expected that the similar relationship between the surface temperature and the inversion strength will hold true for summer. This is also clearly reflected in Fig. 6.

\subsection{The summer of 2007}

The record Arctic sea-ice minimum of summer 2007 has drawn a lot of attention (Deser and Teng, 2008; Drobot et al., 2008; Giles et al., 2008; Kay et al., 2008; L'Heureux et al., 2008; Perovich et al., 2008; Schweiger et al., 2008; Vihma et al., 2008; Zhang et al., 2008; Kauker et al., 2009; Kay and Gettelman, 2009; Lindsay et al., 2009). The roles of clouds, radiation, circulation, atmospheric preconditioning and icealbedo feedback, etc., and their relevance in the context of long-term changes in the Arctic sea ice and the 2007 ice minimum event have been studied extensively over the past few years, using both modeling and observational approaches. Since changes in the inversion strength and its inter-annual

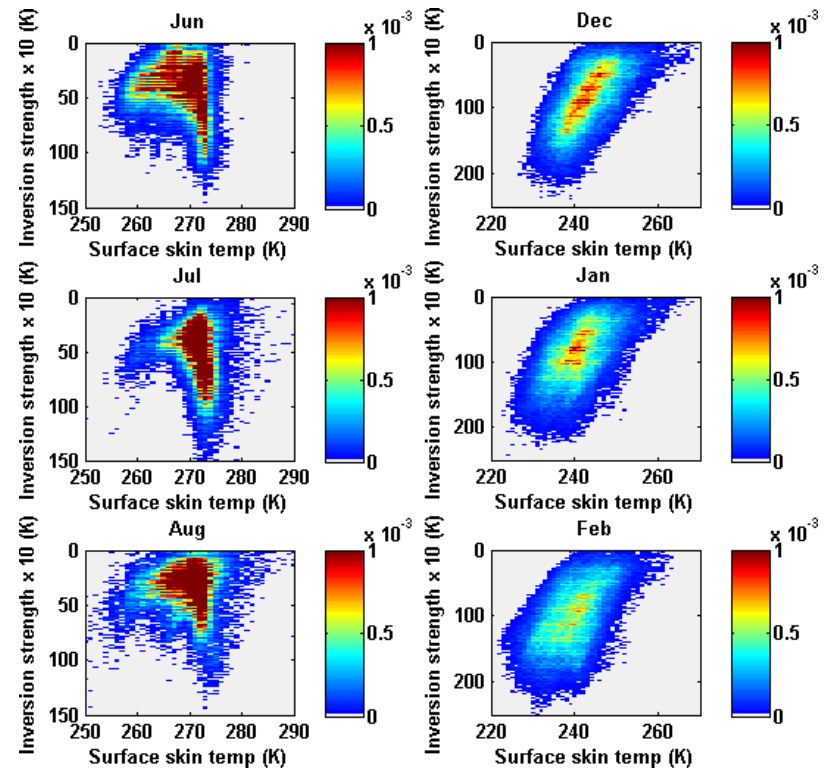

Fig. 6. The joint histograms of inversion strength and surface temperature for summer (left column) and winter (right column) months. Note that the $\mathrm{X}$ and $\mathrm{Y}$ axes are different for summer and winter months and inversion strength is multiplied by 10 . Each temperature-temperature bin is normalized by the total number of observations in the entire histogram.

variability are the manifestations of the interplay of these various atmospheric processes, the aim of this section is to provide some further crucial pieces of information in this context.

The spatial pattern of inversion strength and its interannual variability for June, July and Aug months are shown in Figs. 7-9, respectively. In general, the East Siberian Sea and Beaufort Sea show high inversion strengths in June and July for all years $(>5 \mathrm{~K})$. However in 2007 , the mean inversion strength over the Beaufort Sea shows a conspicuous enhancement ( $>6 \mathrm{~K}$ ) in June, while in July, almost the entire Arctic Ocean shows a strong enhancement in the mean inversion strength. To investigate further, the vertical temperature anomalies for the summer 2007 months are shown in Fig. 10. These are calculated as monthly mean deviations in 2007 from the average of the remaining years. The lower and mid-troposphere was warmed by 1.5 to $3.0 \mathrm{~K}$ in the summer months $(2003,2004,2005,2006$, and 2008). Note that the warming was not restricted to the lowermost troposphere, and observed up to $400 \mathrm{hPa}$ level. Kay et al. (2008) have shown that the zonal and the vertical structure of the temperature over Arctic shows similar warming pattern in the summer months of 2007 when compared to the previous year. Figure 10 shows that the month of June experienced the strongest warming in the lower troposphere which steadily decreased till September. Kay and Gettelman (2009) using radiosonde and AIRS data over the Barrow station also show similar feature for the summer of 2007. 

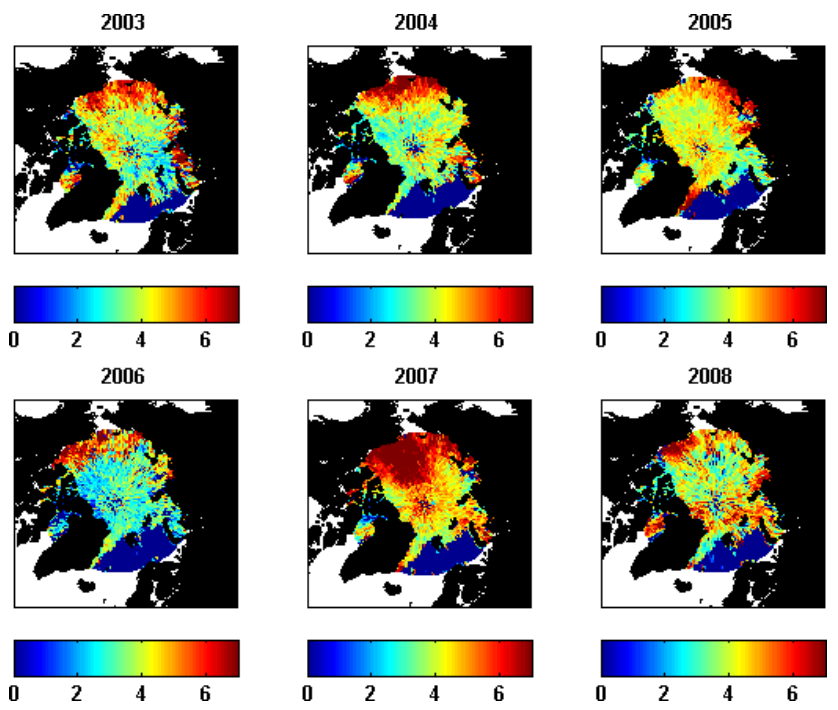

Fig. 7. Inter-annual variations in the inversion strength (in $\mathrm{K}$ ) for the month of June. Notice that the year 2007 stands out clearly.
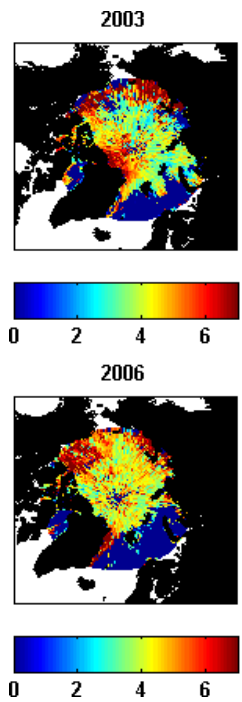
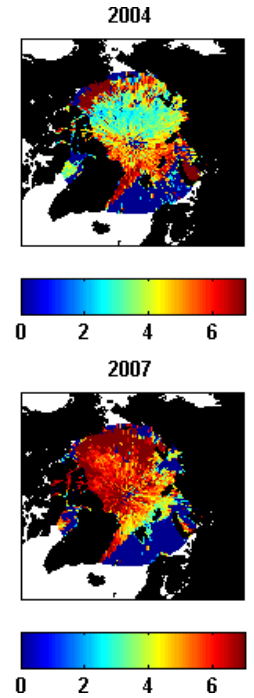
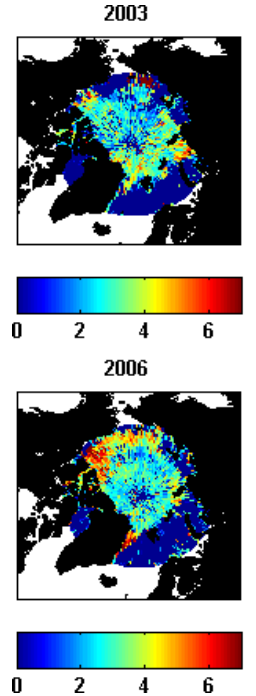
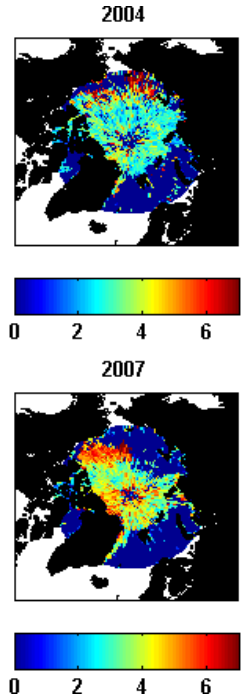
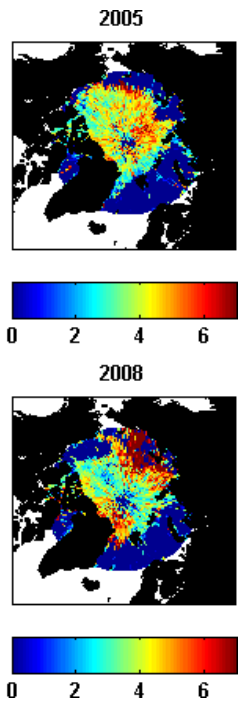

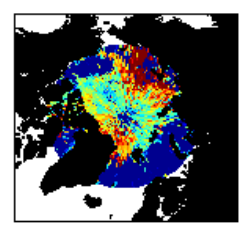

Fig. 9. Same as in Fig. 7, but for the month of August.

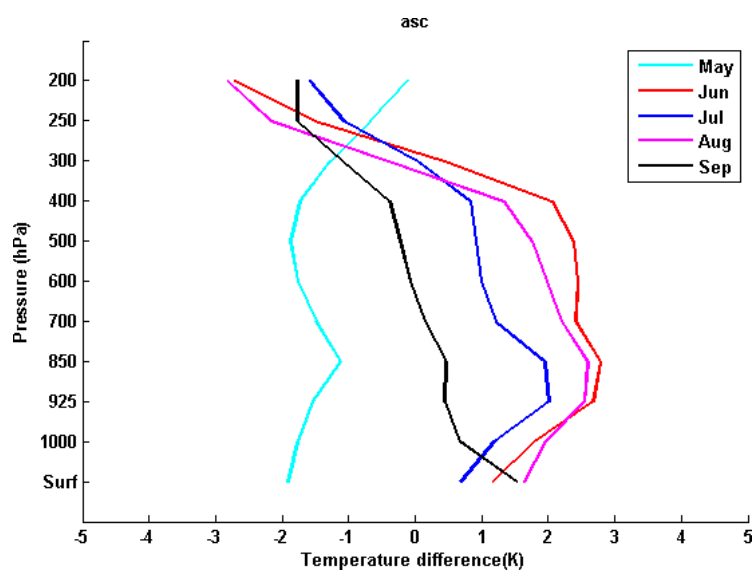

Fig. 10. The vertical structure of the monthly mean temperature anomalies during the summer months of year 2007. The remaining years $(2003,2004,2005,2006$, and 2008) are used to calculate the monthly mean vertical temperature profiles. The data are averages over the entire study area.

ditions compared to summer). However, it is important to note that spatial patterns of inversion frequency and strength (Figs. 2 and 5) do not show footprints of such different sampling, thus hinting at the robustness of our results. These numbers represent about 10 to $40 \%$ of all AIRS profiles are used for the analysis. Additionally, there are two aspects that are worth mentioning here in support of the robustness of the large scale statistics derived from these L3 data; a) only good quality retrievals are used when aggregating L2 data into L3, and b) the sun-synchronous orbital configuration of Aqua satellite results into data being available from multiple orbits (14 per day) at very high latitudes, thus increasing the statistical significance of L3 averages. Therefore, we argue that the statistics presented here using the vertical and 
spatial resolutions of the L3 data are sufficient and relevant to allow direct comparison of our results with the statistics from most of the climate models.

Our definition of inversion includes surface-based and elevated inversions and near-isothermal situations in the lower troposphere. The categorization into different inversion types is possible using temperature profiles from the L2 Support Product provided at 100 vertical levels. However, this product is not rigorously validated yet. In future, it would be interesting to explore this issue further. One source of uncertainty could be the contamination of fractional clouds in the temperature profiles. However, the bias induced due to such situations is expected to be of very small magnitude (Susskind et al., 2006). We rely on the AIRS cloud clearing and have used profiles only when cloud fraction is zero. Thus the statistic presented here is essentially for clear-sky conditions only.

\section{Conclusions and outlook}

Since the changes in the inversion frequency and strength could provide direct hint of the climate change in Arctic and also influence the related processes, their accurate quantification and monitoring becomes crucial. The AIRS instrument provides a unique opportunity to quantify and monitor the inversion frequency and strength over the Arctic Ocean at unprecedented accuracy and resolutions. For the first time, we quantify these parameters for the summer and winter months of 2003 to 2008 over the entire Arctic Ocean for clear-sky conditions. The results from our analysis are in general agreement with the previous studies that use radiosonde observations or the results from the special campaigns.

The following salient features emerged from our analysis:

1. Although the inversion frequency along the coastal regions in the Arctic decreases from June to August, inversions are still seen in almost every profile retrieved over the inner Arctic region.

2. In winter, inversions are ubiquitous over the inner Arctic and are present in every AIRS profile analysed.

3. When averaged over the entire study area $\left(70^{\circ} \mathrm{N}-\right.$ $\left.90^{\circ} \mathrm{N}\right)$, the inversion frequency in summer ranges from 69 to $86 \%$ for the ascending passes and $72-86 \%$ for the descending passes. For winter, the frequency values are $88-91 \%$ for the ascending passes and $89-92 \%$ for the descending passes.

4. The PDFs of inversion strength for the summer months are narrow and right-skewed (or positively skewed), while in winter, they are much broader.

5. In summer months, the mean values of inversion strength for the entire study area range from 2.5 to $3.9 \mathrm{~K}$, while in winter, they range from 7.8 to $8.9 \mathrm{~K}$. The standard deviation of the inversion strength is double in winter compared to summer.
6. Inversions in the summer months of 2007 were very strong compared to other years. The warming in the troposphere of about 1.5 to $3.0 \mathrm{~K}$ is observed extending up to $400 \mathrm{hPa}$ in the summer months of 2007.

Boé et al. (2009) have shown that most of the models in Coupled Model Intercomparison Project - Phase 3 (CMIP3) overestimate inversion strength in the Arctic and may overestimate the negative longwave feedback. Pavelsky et al. (2010) recently showed that the inversion strength and sea ice concentration are tightly correlated, and declines in sea ice concentration would imply weaker mean inversions in future. In these contexts, it is of utmost importance that the global and regional climate models capture these inversion statistics and the vertical temperature structure as accurately as possible to be able to realistically simulate and forecast the Arctic climate and the potential changes therein. At present, the comparison of inversion statistics presented here with the Rossby Center regional models (Jones et al., $2004 a, b)$ is ongoing. The present study focused on quantifying inversion frequency and strength under only clear sky conditions. We will, however, assess an accuracy of AIRS retrievals under partly cloudy conditions extending previous validation studies using in-situ data from the special campaign, Arctic Summer Cloud Ocean Study (ASCOS, http://www.ascos.se/), which was carried out during AugustSeptember 2008 in the inner Arctic. Few studies also indicate trends in inversion characteristics (Kahl et al., 1996; Liu et al., 2006). It is necessary to revisit such trends using integrated in-situ and satellite datasets to better understand and to relate to the observed climate change in Arctic. The data from the most recent Infrared Atmospheric Sounding Interferometer (IASI) instrument would provide even better vertical resolution so as to resolve different inversion types accurately.

\section{Supplementary material related to this article is available online at: http://www.atmos-chem-phys.net/10/5565/ 2010/acp-10-5565-2010-supplement.pdf.}

Acknowledgements. The authors gratefully acknowledge the AIRS Science Team and GES DISC (NASA) for making the AIRS products freely available for research. This work was supported by the Swedish National Space Board grant.

Edited by: T. Garrett

\section{References}

ACIA: Impacts of a Warming Arctic: Arctic Climate Impact Assessment, Cambridge University Press, New York, 2004.

Boé, J., Hall, A. D., and Qu, X.: Current GCMs' unrealistic negative feedback in the Arctic, J. Climate, 22, 4682-4695, doi:10.1175/2009JCLI2885.1, 2009. 
Bradley, R. S., Keimig, F. T., and Diaz, H. F.: Climatology of surface based inversions in the North American Arctic, J. Geophys. Res., 94, 15699-15712, 1992.

Deser, C. and Teng, H.: Evolution of Arctic sea ice concentration trends and the role of atmospheric circulation forcing, 1979-2007, Geophys. Res. Lett., 35, L02504, doi:10.1029/2007GL032023, 2008.

Divakarla, M. G., Barnet, C. D., Goldberg, M. D., McMillin, L. M., Maddy, E., Wolf, W., Zhou, L., and Liu, X.: Validation of Atmospheric Infrared Sounder temperature and water vapor retrievals with matched radiosonde measurements and forecasts, J. Geophys. Res., 111, D09S15, doi:10.1029/2005JD006116, 2006.

Drobot, S., Stroeve, J., Maslanik, J., Emery, W., Fowler, C., and Kay, J.: Evolution of the 2007-2008 Arctic sea ice cover and prospects for a new record in 2008, Geophys. Res. Lett., 35, L19501, doi:10.1029/2008GL035316, 2008.

Fetzer, E. J.: Preface to special section: validation of Atmospheric Infrared Sounder observations, J. Geophys. Res., 111, D09S01, doi:10.1029/2005JD007020, 2006.

Gao, W., Zhao, F., and Gai, C.: Validation of AIRS retrieval temperature and moisture products and their application in numerical models, Acta Metorol. Sin., 64, 271-280, 2006.

Giles, K. A., Laxon, S. W., and Ridout, A. L.: Circumpolar thinning of Arctic sea ice following the 2007 record ice extent minimum, Geophys. Res. Lett., 35, L22502, doi:10.1029/2008GL035710, 2008.

Jones, C. G., Willén, U., Ullerstig, A., and Hansson, U.: The Rossby Centre regional atmospheric climate model, Part I: Model climatology and performance for the present climate over Europe, Ambio, 33(4-5), 199-210, 2004a.

Jones, C. G., Wyser, K., Ullerstig, A., and Willén, U.: The Rossby Centre regional atmospheric climate model, Part II: Application to the Arctic climate, Ambio, 33(4-5), 211-220, 2004b.

Kahl, J. D. W., Martinez, D. A., and Zaitseva, N. A.: Long-term variability in the low-level inversion layer over the Arctic Ocean, Int. J. Climatol., 16, 1297-1313, 1996.

Kahn, B. H. and Teixeira, J.: A global climatology of temperature and water vapour variance scaling from the Atmospheric Infrared Sounder, J. Climate, 22, 5558-5576, 2009.

Karlsson, K.-G. and Dybbroe, A.: Evaluation of Arctic cloud products from the EUMETSAT Climate Monitoring Satellite Application Facility based on CALIPSO-CALIOP observations, Atmos. Chem. Phys., 10, 1789-1807, doi:10.5194/acp-10-17892010, 2010.

Kauker, F., Kaminski, T., Karcher, M., Giering, R., Gerdes, R., and Voßbeck, M.: Adjoint analysis of the 2007 all time Arctic sea-ice minimum, Geophys. Res. Lett., 36, L03707, doi:10.1029/2008GL036323, 2009.

Kay, J. E. and Gettelman, A.: Cloud influence on and response to seasonal Arctic sea ice loss, J. Geophys. Res.-Atmos., 114, D18204, doi:10.1029/2009JD011773, 2009.

Kay, J. E., L'Ecuyer, T., Gettelman, A., Stephens, G., and O'Dell, C.: The contribution of cloud and radiation anomalies to the 2007 Arctic sea ice extent minimum, Geophys. Res. Lett., 35, L08503, doi:10.1029/2008GL033451, 2008.

L'Heureux, M. L., Kumar, A., Bell, G. D., Halpert, M. S., and Higgins, R. W.: Role of the Pacific-North American (PNA) pattern in the 2007 Arctic sea ice decline, Geophys. Res. Lett., 35, L20701, doi:10.1029/2008GL035205, 2008.
Lindsay, L. W., Zhang, J., Schweiger, A., Steele, M., and Stern, H.: Arctic sea ice retreat in 2007 follows thinning trend, J. Climate, 22, 165-176, 2009.

Liu, Y. and Key, J. R.: Detection and analysis of clear-sky, lowlevel atmospheric temperature inversions with MODIS, J. Atmos. Ocean. Tech., 20, 1727-1737, 2003.

Liu, Y., Key, J. R., Schweiger, A., and Francis, J.: Characteristics of satellite-derived clear-sky atmospheric temperature inversion strength in the Arctic, 1980-96, J. Climate, 19, 4902-4913, 2006.

Mernild, S. H. and Liston, G. E.: The influence of air temperature inversions on snowmelt and glacier mass-balance simulations, Ammassalik Island, SE Greenland, J. Appl. Meteorol. Clim., 49, 47-67, 2010.

Olsen, E. T., Susskind, J., Blaisdell, J., and Rosenkranz, P.: AIRS/AMSU/HSB version 5 level 2 quality control and error estimation, JPL/NASA, California Institute of Technology, Pasadena, USA, 15 pp., 2007a.

Olsen, E. T., Granger, S., Manning, E., and Blaisdell, J.: AIRS/AMSU/HSB version 5 level 3 quick start, JPL/NASA, California Institute of Technology, Pasadena, USA, 25 pp., $2007 \mathrm{~b}$.

Pavelsky, T., Boé J., Hall, A., and Fetzer, E.: Atmospheric inversion strength over Polar Oceans in winter regulated by sea ice, Clim. Dynam., doi:10.10007/s00382-010-0756-8, available at: http:// www.springerlink.com/content/8731208kn3058174/, 2010.

Perovich, D. K., Richter-Menge, J. A., Jones, K. F., and Light, B.: Sunlight, water, and ice: extreme Arctic sea ice melt during the summer of 2007, Geophys. Res. Lett., 35, L11501, doi:10.1029/2008GL034007, 2008.

Schweiger, A. J., Zhang, J., Lindsay, R. W., and Steele, M.: Did unusually sunny skies help drive the record sea ice minimum of 2007?, Geophys. Res. Lett., 35, L10503, doi:10.1029/2008GL033463, 2008.

Sedlar, J. and Tjernström, M.: Stratiform cloud-inversion characterization during the Arctic melt season, Bound-Lay. Meteorol., 132, 455-474, doi:10.1007/s10546-009-9407-1, 2009.

Serreze, M. C., Kahl, J. D., and Schnell, R. C.: Low-level temperature inversions of the Eurasian Arctic and comparisons with Soviet drifting stations, J. Climate, 5, 615-630, 1992.

Susskind, J., Barnet, C., Blaisdell, J., Iredell, L., Keita, F., Kouvaris, L., Molnar, G., and Chahine, M.: Accuracy of geophysical parameters derived from Atmospheric Infrared Sounder/Advanced Microwave Sounding Unit as a function of fractional cloud cover, J. Geophys. Res., 111, D09S17, doi:10.1029/2005JD006272, 2006.

Tjernström, M. and Graversen, R. G.: The vertical structure of the lower Arctic troposphere analysed from observations and ERA40 reanalysis, Q. J. Roy. Meteor. Soc., 135, 431-443, 2008.

Vihma, T., Jaagus, J., Jakobson, E., and Palo, T.: Meteorological conditions in the Arctic Ocean in spring and summer 2007 as recorded on the drifting ice station Tara, Geophys. Res. Lett., 35, L18706, doi:10.1029/2008GL034681, 2008.

Zhang, J., Lindsay, R., Steele, M., and Schweiger, A.: What drove the dramatic retreat of Arctic sea ice during summer 2007?, Geophys. Res. Lett., 35, L11505, doi:10.1029/2008GL034005, 2008. 